\title{
TRADICIÓN Y TRANSGRESIÓN EN LOS CUENTOS DE JULIO RICCI
}

\author{
POR \\ NOEMÍ ULLA \\ Universidad de Buenos Aires
}

En la literatura del Río de La Plata los cuentos de Julio Ricci ${ }^{1}$ podrían definirse como unos de aquellos ligados de manera muy estrecha al realismo de tradición urbana. Sin embargo, la crítica a la burocracia, a la inercia del sistema social, al desarrollo de la tecnología y sus efectos en un país poco desarrollado, revelan con ironía y humorismo, matices del grotesco y del absurdo que emparientan más de una de sus invenciones con la literatura fantástica. Fecundo y tardío, este escritor uruguayo reúne en el ceñido período de diecisiete años, cinco libros de cuentos. ${ }^{2}$

Muchas veces fiel a la construcción de los cuentos cultivados por los grandes maestros del género, otras veces las narraciones de Julio Ricci se aproximan al relato, introducen cartas ("El gamexán" y "El laburo", El Grongo), son cartas los relatos mismos ("La carta", Cuentos civilizados) o aparecen como anotaciones ("Las cerillas II", Cuentos civilizados). Al mismo tiempo suelen incorporarse al texto referencial de otros campos, como tablas de valores, listas, balances, cuestionarios, cuadros, noticias necrológicas, fragmentos de alguna noticia periodística, y esto parecería traducir una necesidad - casi hiperrealista-de consignar la verosimilitud, pero también de burlarse de lo Kitsch, en la transcripción de ingenuos textos de tarjetas, invitaciones, participaciones, todos ellos gráficamente señalados. Estas presencias, en cuentos como "Los domingos no los paso más en casa de mi señora", "El Shoijet", "Los coleccionistas de escupidas", "El profesor" (El Grongo), "Las ideas parsimoniosas del Señor F.

\footnotetext{
${ }^{1}$ En ocasión del Coloquio Internacional sobre Tango, que se realizó en Toulouse en noviembre de 1984, Giovanni Meo Zilio me obsequio su estu dio "El neorrealismo de Julio Ricci entre onirismo y gestualidad: apuntes estilísticos" (separata de la Revista Iberoamericana, 123-124, abril-septiembre 1983). Hasta entonces desconocía a Julio Ricci, y la dificultad para conseguir sus libros en Buenos Aires me hizo recurrir directamente al Uruguay. Esto pone de manifiesto, una vez más, la paradoja de estos países hermanos en cercanía y notablemente incomunicados en su producción literaria. 2 Julio Ricci, Los maniáticos (Montevideo: Alfa, 1970); El Grongo (Montevideo: Géminis, 1976); Ocho modelos de felicidad (Buenos Aires: Macondo, 1980); Cuentos civilizados (Montevideo: Géminis, 1985); Los mareados (Montevideo: Monte Sexto, 1987).
} 
Szomogy" (Ocho modelos de felicidad) imponen una especie de orden hiperbólico que da a la literatura el carácter ilusorio de documento, transgrediendo aquel orden supuesto de las "bellas letras", contra el cual el autor manifiesta -en las mismas narraciones y en el prólogo el El Grongo- su desacuerdo.

A pesar de la variedad que ofrecen sus cuentos por los argumentos y los desarrollos igualmente diversos, ${ }^{3}$ la relación con ellos tendrá aquí un eje preferencial, que es el de mi hipótesis de trabajo sobre las particularidades de la escritura rioplatense en el marco de los años sesenta y setenta.

\section{EL LÉXICO EN EL CONTEXTO DE LA ESCRITURA LITERARIA RIOPLATENSE}

Enel nivel léxico los textos de Julio Ricci registran italianismos, lunfardismos y uruguayismos, ${ }^{4}$ pero además prestan oído a una nueva entonación, la del inmigrante europeo no español ni italiano sino húngaro, al centroeuropeo que habla el español rioplatense imprimiéndole su propio acento nativo.

Las observaciones sobre la entonación del extranjero que usa un castellano inseguro aparecen en sus cuentos y recuerdan al lingüista que hay en él; ${ }^{5}$ su saber en este campo compone un rasgo - entre otros - de su escritura, la de la mímesis del habla del acento no nativo, como lo hicieron hasta 1930 los escritores que intentaban exaltar nuestra identidad rioplatense o simplemente registrar la presencia de lainmigración extranjera. EnEl juguete rabioso, Roberto Arlt transcribía usos sintácticos y fónicos del andaluz, mediante el zapatero que inicia a Silvio Astier en el placer de la lectura, y particularidades fónicas y sintácticas del italiano dialectal a través de la pareja dueña de la librería donde trabaja el protagonista. En "Hombre de la esquina rosada" Jorge Luis Borges presentaba el discurso coloquial rioplatense de típica entonación criolla y orillera en el monólogo del narrador. Felisberto Hernández, desde aquellos textos que más tarde se compilaron con el nombre de Primeras invenciones (1969) y que se publicaron entre 1925 y 1939 , escribió con un español rioplatense sin huellas de italianismos ni lunfardismos, en tanto que Juan Carlos Onetti registró lunfardismos e italianismos en el orden léxico y sintáctico a partir de $E l$ pozo (1939). ${ }^{6}$ La presencia del acento de los inmigrantes, que tanto ha impregnado la producción del sainete y que se tuvo muy en cuenta para dar al

\footnotetext{
' Fernando Ainsa, José Angeles, Fernando Butazzoni y Martha Canfield, entre otros, han observado diversos aspectos de la narrativa de Julio Ricci.

${ }^{4}$ Giovanni Meo Zilio, en "El neorrealismo de Julio Ricci entre onirismo y gestualidad: apuntes estilísticos", op. cit. señala con precisión la diversidad de este léxico.

s Julio Ricci (Montevideo, 1921) egresó del Instituto de Estudios Superiores y su especialidad es la Lingüratica. Ejerció la docencia en el Instituto Iberoamericano de Gotemburgo (Suecia), en Florida State University Tallahassee (Estados Unidos), en F.S.U. Study Center of Florencia y en Uruguay, hacia fines de 1985.

' Noemi Ulla, La escritura coloquial en torno a 1930. Cuatro textos iniciales rioplatenses, (Buenos Aires: Catálogos) (en prensa).
} 
discurso color local - los Cuentos de Fray Mocho, a fines y a principios de siglo, sabían que esto era una garantía para la recepción por parte del público ${ }^{7}$ - fue también, en los alrededores de 1920 y 1930, un rasgo común a las letras de los tangos, cuando éste gozó de su esplendor ciudadano. ${ }^{8}$ Los cuentos de Julio Ricci, en especial los que agrupan Los maniáticos y El Grongo, se alinean en esta vertiente de textos que dan - sin que esto sature el texto- las variantes lingüísticas rioplatenses (voseo y sus formas verbales correspondientes), las particularidades de un Montevideo también cosmopolita, señalado a veces gráficamente en la entonación de un húngaro:

Tótal, para qué quéremos dos - termino, sin poder evitar su fuerte acento húngaro de siempre (El Grongo 56).

-Mire, yo he vénido de cánciyéria, pues cónfieso gran ádmiración por su páis_expuso con un acento que detecté era húngaro (Ocho modelos de felicidad, 119).

Montevideo, asimismo Argentina y en especial Buenos Aires, es el referente geográfico que se nombra, se exhibe, se repite, tratando de crear la ilusión de lo verosímil en la trama del texto, de manera singular en Los maniáticos, El Grongo y Ocho modelos de felicidad. Este "callejero" que es el narrador típico de sus cuentos, conoce los bares, las plazas, los lugares apartados, el centro, los parques, que distingue el Puerto, el Cerro, Pocitos, Malvín, Villa Muñoz, Punta Gorda, Carrasco, la Ciudad Vieja de Montevideo, que nombra los barrios y las calles, que se detiene en connotaciones axiológicas e ideológicas, en observaciones de orden fisiológico -que nunca abandona la presentación del cuerpo-ingresa en la tradición de los narradores de la literatura urbana o del montevideanismo,, como la designó Arturo Sergio Visca, ${ }^{9}$ de la que Mario Benedetti es quizás el referente literario más próximo.

A mí en realidad me gustaba mucho caminar por 18 porque veía las luces de los semáforos, algunas que otras viejas que salían de las tiendas [...] esa mezcla heterogénea de blancos, menos blancos, morochos, pardos, etc. Eran rengos, bien vestidos (algunos), andrajosos (algunos más), mujeres con piernas con elefantiasis (siempre me preguntaba por qué tantas) y coches, desorden y vida entreverada (Ocho modelos de felicidad 91 ).

\footnotetext{
${ }^{7}$ Noemí Ulla, véanse los capítulos sobre Fray Mocho: "El registro oral", "La escritura para la recepción", "El discurso amoroso de criollos e inmigrantes", en La escritura coloquial (en prensa).

${ }^{8}$ El tango y sus letras están en los cuentos de Julio Ricci como presencia que late en el ritmo de la ciudad. En "El apartamento" (El Grongo) la evocación del tango y sus intérpretes se da como homenaje (83-84), tanto como el nombre Los mareados, su último libro de cuentos, al tango homónimo.

${ }^{\ominus}$ Arturo Sergio Visca, "Panorama de la actual narrativa uruguaya", Ficción, 5 (Buenos Aires, enero-febrero 1957), y "Nativismo y urbanismo en la literatura uruguaya de hoy", Comentario, 54 (Buenos Aires, mayo-junio, año 14, 1967).
} 
Así reflexiona un empleado de banco que asiste a un compañero de trabajo, cuyo machismo se ve absorbido y degradado, con mordacidad y tragedia, por una mujer autoritaria.

La puntual presencia de la ciudad con sus exteriores se advierte en los cuentos de El Grongo:

El frío siempre húmedo y pegajoso de los inviernos montevideanos (117). ... esas tardes lluviosas y grises del invierno montevideano (22),

también como un lugar del que será necesario huir, mediante el discurso referido de los "pesimistas":

... fugar de Montevideo, de ese Montevideo gris y anémico, de ese Montevideo de veredas rotas, calles deshechas, casas sin pintura, basurales inmundos y yiras mañaneras (El Grongo, 125).

El referente explícito o la "ilusión" del referente explícito se consigna al detalle, insistiendo en la necesidad de que el verosímil, con todo su peso, logre sus efectos: representar también los lugares que frecuenta, los artículos que consume y los lugares donde los consume la amplia clase media, la clase baja, los marginales, observados todos ellos por ese "caminador" que afirma en un texto de Los mareados: "Las ventanas de los cafés eran siempre algo así como pequeños palcos ante el espectáculo del mundo" (20).

La serie de referentes precisos - del tipo que señalo al pie ${ }^{10}-$ va desapareciendo en los úl timos libros, casi no existen en Cuentos civilizados y Los mareados, salvo en uno u otro texto, ya que la tendencia a marcar la indiferenciación, la tecnificación y la masificación opera como intensificador en una escritura que va connotando, en el triunfo del apetito o la incentivación del consumo, la desaparición del valor que diferencia lo local, la procedencia racional de lo extranjero, en individuos que aún no habían sido absorbidos ( Los maniáticos, El Grongo, Ocho modelos de felicidad) por la dominación y el desarrollo mayor de las empresas extranjeras en el país. En tal sentido, la última escritura de Julio Ricci parece acertar con uno de los pronósticos que

\footnotetext{
${ }^{10}$ Leemos en Los maníaticos: "las alpargatas azules que había comprado en Soler" (23), "el pollo relleno que compraste ayer en el Lion d'Or" (25), "Ella se tapaba la cabeza con la frazada Campomar" (62), "una especie de palangana chata que compré un domingo en la feria de Tristán Narvaja" (71); en El Grongo: "fueron a Alta Gracia y las Cataratas del Iguazú en luna de miel" (17), "hicimos el viaje de bodas a Buenos Aires (9), "El cognac Aubigny que le habian traido de Buenos Aires". Los hombres no se reúnen y toman simplemente un cafe, sino en "el Facal Chico" (Ocho modelos de felicidad, 83), en el de "Arenal Grande" (67), "en el Sorocabana" (14), "el bar Welcome de la calle Piedras" (15) de Los maniáticos; en "un bar de Libertad y Br. España. En el Congreso. O tal vez en el Fray Mocho", (Los mareados, 26), "en el cafe de Ellauri” (El Grongo, 10).
} 
Ángel Rama hacia en 1965, respecto del provincianismo cultural. ${ }^{11}$ En efecto, los recursos descriptivos, los referentes tan puntuales de las primeras narraciones, incluso y sobre todo, el afecto que denotaban aquellos connotadores geográficos, topográficos, de los libros arriba mencionados, están en representativa ausencia -en general-por la masificación que reflejan, tanto como el nombre de su penúltimo libro Cuentos civilizados. Textos allí incluidos, como "La pared", "La necesidad de ser esquizofrénico", "El cronista de obituarias", "La jerarqứ", "El gerente", "La baba", y aún "La carta", son testimonio de la tecnificación y de la escritura que registra los correspondientes referentes con ironía y humorismo: "los necesarios psicofármacos(Nubex, Fildopon, Stupident, Piltrafac, Dormentin, etc.)" (Cuentos civilizados, 20). Precisamente en "La pared", símbolo de las operaciones que montan y desmontan papeles y empleados, el narrador observa ideológicamente:

Con la nueva tecnología que había sido introducida en el país y que provenía del extranjero, de los benditos paises desarrollados, la pared longitudinal podía alzarse y tirarse diez veces por día. Se esperaba acelerar más el ritmo (Cuentos civilizados, 27).

y sin partidismos simplificadores:

El que ha sido tocado por la varita mágica de una jerarqufa es en cierto modo el noble en un país socialista (Cuentos civilizados, 23).

Uno de los narradores de Los mareados, un ascensorista -que habiendo quedado sin vivienda deambula buscando piezas de alquiler sin resolverse por ninguna ("La pieza") - es quien percibe, en el silencio ya deshumanizado, la cosificación que invade el ámbito de su trabajo al cambiarse el viejo ascensor por el nuevo. La perfección electrónica ha anulado su capacidad y su intervención; la gente, por lo mismo, entra y sale del ascensor en forma también automática y él no recibe los "gracias, hace calor, hace frío" que acompañaban antes su rutina, porque todo es futural, adjetiva irónicamente el narrador incorporando una de las tantas invenciones y combinaciones lingüísticas que se diseminan con generosidad en los textos. ${ }^{12}$

\footnotetext{
11 “Imposible pensar la cultura de nuestro país en su próxima etapa de desarrollo dinámico sin la implicancia de las condiciones económicas y espirituales de la actual civilización norteamericana, aunque no necesariamente sociales, dada nuestra condición (Toynbee) de proletariado externo de ella" (Ángel Rama, "Del provincianismo cultural”, en Carlos Real de Azúa, selec., El Uruguay visto por los uruguayos (Montevideo-Buenos Aires: Centro Editor de América Latina, 1968), t. I, 158.

${ }^{12}$ Leemos en Los maniáticos: "cavilando y recavilando" (60), "coleantes" (43), "grisoides" (45); en El Grongo: el mismo término Grongo es invención del autor, "futuro futurible" se acompaña, como otras veces, del comentario metadiscursivo "como decían los optimistas"; en Ocho modelos de felicidad: "variedades engullicias" (32), "universo sexivo" (87), "se
} 


\section{LA SINTAXIS LOCUTIVA}

Como sus compatriotas Felisberto Hernández, Juan Carlos Onetti, Mario Benedetti y como los argentinos Julio Cortázar, Manuel Puig, Germán Rozenmacher, Julio Ricci presenta en muchos tramos de sus cuentos y en cuentos enteros, una sintaxis particularmente coloquial. La sintaxis locutiva que participa más del habla que de la escritura con sintaxis literaria, y que suscita teorizaciones en lingüistas estadounidenses que consideran el habla y la escritura del idioma inglés en la literatura de ese mismo idioma, ${ }^{13}$ tiene en el Río de La Plata, a mi criterio, si no una génesis, sí una práctica de mayor énfasis en la década de 1960, sustentada en convicciones ideológicas socialistas que fueron arraigándose en forma notoria en algunos escritores, a partir del triunfo de la revolución de Cuba (1959) y la propuesta de hacer una literatura latinoamericana afianzada en descubrir las particularidades del español en los países americanos de habla hispana.

La brevedad de este trabajo sólo me permite puntualizaciones sumarias en torno de tan amplio tema, que en otra parte de mi investigación desarrollo; ${ }^{14}$ valga por ahora una casi obvia aserción: el reconocimiento del peso social de los marginados afirmó el derecho a documentar las particularidades de su habla en la escritura de los narradores de los años sesenta. Y ésta es buena parte de la herencia de Julio Ricci, cuya entonación coloquial se ve favorecida a menudo por la elección de un yo narrador - casi siempre es el observador callejero típicoque seduce a la concurrencia con el ritmo presuroso de su relato, como seducía el narrador de los cuentos de Montevideanos de Mario Benedetti. En Cuentos civilizados el ritmo precipitado parece acentuarse. Otras veces el narrador sorprende con el desarrollo de un discurso cuidadosamente evocativo, de ritmo lento y elaborado, y la utilización de ciertas interferencias léxicas y que cambian el punto del ritmo, al dinamizarlo, como en "El Shoijet": "Se me prendió la lamparita", "yo paraba la oreja", "aunque haciéndome el zonzo", "no daba pie con

incriminaban, como dicen las seriales americanas" (107), "un día de despegue, como hubiera dicho uneconomista" (115); en Cuentoscivilizados: "funcionariado" (19), "jefaturial" (22), "insonrientes" (24), "minirrománticas" (129), "eg6́logo" (98), ironiza sobre el psicoanálisis. En Los mareados: "orgasmorreaba" (11), "criptoinvolucrados" (13), "introatención" (33), "minifeliz" (45), "denuedo limpieril" (50), "torta seisvelitera" (51), se mantuvoescuchante" (63), "maullidosalimentofilos" (80), "sexollamadas" (80), "neocasado" (112), "un moralímetro" (55). (Los subrayados son míos).

${ }^{13}$ Douglas Biber, "Spoken and Written Textual Dimensions in English: Resolving the Contradictory Findings”, Language, v. 62, $\mathrm{n}^{2} 2$ (1986), 384-414. También el investigador checo Emil Volek desarrolla un estudio sobre el lenguaje coloquial en la estructura narrativa en Metaestructuralismo (Madrid: Fundamentos, 1985), 95-122.

14 "El lenguaje rioplatense en los últimos cincuenta años. Las transcripciones del habla en los escritores del 30: su expansión y metamorfosis en la década del 60", es el trabajo que realizo en el Consejo Nacional de Investigaciones Cientificas y Técnicas. 
bola", "quué se yo!" (El Grongo). Estos recursos, dentro de un texto de sintaxis literaria, rompen graciosamente el ritmo del relato, y los he encontrado en un tipo de escritura como la de Armonia Somers, ${ }^{15}$ nada vuelta hacia la presencia ausente del destinatario ${ }^{18}$ en tanto que estos contrastes son escasos en los textos de Julio Ricci, ya que la práctica constante del discurso donde el destinatario está siempre o casi siempre implícito, los vuelve infrecuentes.

En "El marcapaso" (Ocho modelos de felicidad) el narrador inicia la presentación de Juanita Pérez con sintaxis coloquial que de inmediato quiebra para pasar a la de la literatura tradicional, oponiendo el juego del contrapunto de dos discursos que se relacionan, de algún modo, con las protagonistas y que no obedece al mero azar. Hay en sus textos, como también en los de Mario Benedetti y Juan Carlos Onetti, un saber de las diferencias que la entonación oral del rioplatense marca con claridad en el idioma español, de los italianismos provenientes de la inmigración, de los lunfardismos que caracterizan el habla ciudadana, de los vulgarismos y de la sintaxis locutiva que, en la escritura y vueltos al destinatario, hacen que el rioplatense se reconozca de inmediato. De otro modo que en el texto de Roberto Arlt o de Manuel Gálvez, entre otros, cuyos lunfardismos aparecian casi siempre encomillados, el texto de Julio Ricci asume la integridad de la enunciación, sin marcar comillas en los lunfardismos. ${ }^{17}$

\section{LA RECEPCION DEL INMIGRANTE}

La evidente simpatía por aquellos marginados de 1936 - la llamada "ley de indeseables" restringióla inmigración al país-se advierte en este narrador que no clausura su registro en la intimidad local, sino que se abre a lo cosmopolita. La presencia de los extranjeros no es exclusiva en sus textos, pero sí notoria y se apega a un referente explícito. Observa Juan Antonio Oddone ${ }^{18}$ que además de los inmigrantes habituales, como los italianos y los españoles, una oleada de polacos, rumanos y bálticos, serbios y croatas, alemanes y austro-húngaros, sirios y armenios llegó al Uruguay en los años 1930, en la etapa mayor de la última inmigración espontánea, asentándose especialmente en Montevideo y aportando "una nota de inusitada diversificación cultural y religiosa" (109).

\footnotetext{
${ }^{15}$ NoemiUlla, "Metonimia y connotaciones ideologicas en el discurso amoroso de Requiem para Goyo Ribera', de Armonía Somers", en Claves para Armonta Somers (Montevideo, Linardi y Risso) (en prensa).

${ }^{16}$ Tomo la designación de Gérard Genette, Figures III (Paris: Seuil, 1972), 262.

17 En su estudio sobre la cita, Antoine Compagnon (La seconde main ou le travail de la citation, Paris: Seuil, 1979) ha definido con exactitud el texto que prescinde de los polimorfismos.

${ }_{18}$ Juan Antonio Oddone, "Inmigración y modernización", en Carlos Real de Azúa, selec., El Uruguay visto por los uruguayos (antologia)(Montevideo-Buenos Aires: Centro Editor de América Latina, 1968), t. 2, 109.
} 
Más de una de las narraciones de este escritor exaltan la cultura del pueblo judío o de otras del centro de Europa, pero también suelen ejercer la ironía, la burla, y hasta un piadoso humorismo, en rápidas observaciones. En "Las ideas parsimoniosas del señor F. Szomogy" la altivez de la madre y el hijo muestran su superioridad ante los latinoamericanos (Ocho modelos de felicidad 13); en "Las amistades del Sr. Szomogy" el narrador protagonista marca la excesiva corrección de su asiduo visitante del consulado "No lograba ir más allá de la corrección rígida y repetida, mono-estructurada, herencia quizá de un feudalismo de boyardos torturadores y de atilas avasallantes" (Ocho modelos de felicidad 121); en "El regalo para el amigo de Hungria" el narrador imagina a su amigo húngaro con la apariencia de un perro europeo "desconocido aqu" (El Grongo 58). Pero el verdadero homenaje parece darlo el cuento "El Shoijet" (El Grongo 19-33), cuya descripción del rabino es un singular retrato literario, con la mirada de asombro del niño no judío que observa la particularidad de otra religión y otra cultura (23). Como en ninguno de sus textos, el afecto y la exaltación se encuentran reunidos en una suerte de investigación y viaje hacia el encuentro de un amigo de infancia. La búsqueda del amigo perdido, Lázaro Dorón, lleva al narrador - hombre de setenta años - a realizar un breve vuelo de Montevideo a Buenos Aires, que por obra de la misma búsqueda - caminatas por la calle Tucumán porteña y sus laterales, por el barrio del Once ("las calles del ghetto como le llamaban los porteños" El Grongo 26)— se transforma de manera prodigiosa en otro viaje hacia el descubrimiento de un mundo maravilloso y deseado:

Los nombres nomás me tralan reminiscencias de cosas extrañas, de ciudades imaginadas, de países casi feéricos: Mercería Koldonski, Ropería Malamud, Bazar Goldberg, Sastrería Chicurel ... (El Grongo 26).

La fascinación por el bazar ("los bazares asiáticos llenos de maravillas y misterios infinitos”, El Grongo 27) que esconde en su interior sorpresas a descubrir, ${ }^{19}$ muestran a ese personaje típico de sus cuentos: el caminador, el hombre que recorre la ciudad y penetra en los recovecos para conocer sus historias y los modos de vida de la gente.

\section{EL CUERPO Y SU LENGUAJE}

Quizás la real transgresión al “esteticismo", la verdadera marginalidad en los cuentos de este escritor uruguayo esté en la insistencia de un motivo que en

\footnotetext{
${ }^{10}$ Walter Benjamin su po descubrirel vértigo de esa bú squeda en los bazares y en las calles, en sus escritos sobre Baudelaire en el Paris del Segundo Imperio, en Poesía y capitalismo. Iluminaciones 2 (Madrid: Taurus, 1980), segunda edicion, especialmente el capítulo "El flâneur".
} 
los años de la década del sesenta se desarrolló con timidez. Julio Cortázar, David Viñas, Manuel Puig, entre otros en Argentina, Armonía Somers, L. S. Garini, Cristina Peri Rossi, entre otros en Uruguay, presentaban ya el lenguaje del cuerpo. Julio Ricci llevará esto al énfasis, centrando la atención en las necesidades meramente orgánicas, y noen la sexualidad, que la narrativa de los autores mencionados sí se había atrevido a abordar, y que está casi ausente en los textos de este narrador.

Los textos que componen Los maniáticos -junto con El Grongo y Ocho modelos de felicidad - reiteran con holgura lo "bajo", las necesidades naturales y sus olores, tan propios de la literatura del realismo grotesco, que sin embargo la tradición urbana - y valga el adjetivo- donde se sitúa la narrativa de este autor, ha desdeñado en su mayoría. Tal vez un extraño antecedente podría reconocerse en Jorge Luis Borges y Adolfo Bioy Casares, quienes en Un modelo para la muerte (Buenos Aires: Oportet \& Haereses, 1946) y con el seudónimo de B. Suárez Lynch, escandalizaron el entorno literario con un breve y famoso pasaje.

Aunque la mención de Mijail Bajtín ha impreso en los últimos años socorrida obligatoriedad, no puedo evitar la evocación de uno de sus estudios, el que se relaciona con este aspecto que se observa en los textos de Julio Ricci. Me refiero al vínculo existente entre la tradición de la cultura cómica popular ${ }^{20}$ y la faz de lo "bajo corporal" en Rabelais.

El primer cuento de Los maniáticos, "Pivoski", es uno de los retratos más vívidos de un anciano polaco que habita en la miseria y el olvido de la Ciudad Vieja de Montevideo. En la insistente descripción del deterioro del cuerpo y la falta de higiene, hay particular detenimiento:

Pasé y lo segur. Había un intenso olor a vetustez y a podredumbre mezcladas. Se respiraba el olor que hay en las casas que no se ventilan por años y años y parecia como si hubiera un gato o algún otro animal muerto hacía tiempo (Los maniáticos 10-11).

Por la confesión de Pivoski, narrador del cuento, se sabe que el cadáver descansa desde hace años en un baúl de las habitaciones. Pero las sospechas del narrador mientras espera que el anciano abra la puerta de calle, rebelan también su propia fruición en la referencia a las necesidades fisiológicas:

A lo mejor Pivoski estaba orinando o liberando el intestino (10).

Con todo, debajo del catre divisé una escupidera cargada de orines que a lo que parecía oficiaba de excusado (11).

Los olores eran insoportables, la falta de luz [...] pero había en cambio un calor humano inefable, una intimidad inexpresable, que yo habia imaginado siempre

\footnotetext{
${ }^{20}$ Mijail Bajtín, La cultura popular en la Edad Media y en el Renacimiento. El contexto
} de François Rabelais (Barcelona: Barral, 1974). 
como peculiar de la Europa Central y de los Balcanes (11). ... luego abrí la puerta de la habitación de la madre y entro. Había un olor repugnante, único.(20)

Otro de los maniáticos que ve frustradas sus especulaciones con la adquisición de una cámara fotográfica traída de Alemania y que le es robada de inmediato, acompaña esas manías con dificultades fisiológicas que el narrador describe con rigurosa precisión, humorismo y fidelidad al referente:

Recordé entonces que desde hacía años [...] solía ir al baño con la firme decisión de liberar a su intestino de impurezas. Una vez adentro, levanta la tapa, hacía correr el agua, colocaba un papel [...] con el fin de acelerar sus procesos de evacuación (Los maniaticos, 42 ).

Unos minutos más tarde [...] lo cual demostraba que esta vez se había puesto de acuerdo con su intestino (Los maniáticos 42).

... había estado muy seco de vientre ... (Los maniaticos 45).

En el cuento "La cola" la vida de la gente que la compone se transforma en una suerte de infierno, los integrantes esperan poder cumplir determinados trámites, mientras transcurren los inviernos y los veranos infinitos y todo se va degradando:

En general había muy mal olor en torno a los tramitantes y como no existían servicios higiénicos, los insectos se acumulaban [...] Las necesidades se hacian en un baldío cercano y esto aumentaba el bicherio (El Grongo 46).

En un estudio sobre Juan Carlos Onetti, ${ }^{21}$ señalé que en $E l$ pozo las escasas imágenes o referencias corporales aparecen desprovistas de gozo, siguiendo un extraño desdén por la materialidad del cuerpo como productor de placer, y por ligazones con nuestra tradición española y cristiana. Precisamente Angel Rama había observado en la presentación que acompaña a una de las ediciones de $E l$ pozo, ${ }^{22}$ que las "situaciones chocantes" - se refería a las libertades de expresión- y las "violencias verbales" presentes en el texto, no se habían diseminado suficientemente en las obras de los escritores uruguayos. En la narrativa de Julio Ricci ocurre lo contrario, si bien el énfasis y la frecuencia de las precisiones corporales de lo "bajo" son claras, nada está cargado de desagrado, y la naturalidad acompaña estos motivos y hasta a veces, como en el realismo grotesco, convive con el agrado y la ironía o el humorismo. En "Pivoski" el narrador confiesa respecto de la casa del anciano:

\footnotetext{
${ }^{21}$ Noemi Ulla, "El sentido de las imágenes corporales", en Claves para Onetti (Montevideo: Linardi y Risso) (en prensa).

${ }^{22}$ Ángel Rama, "Origen de un novelista y de una generación literaria”, en Juan Carlos Onetti, El pozo (Montevideo: Arca, 1969), 5ª edición, 53-107 (el estudio de Ángel Rama está fechado en 1965).
} 
En casa tenía luz, calefacción, limpieza, todo lo que el mundo y la técnica modernos han dado. Pero faltaba algo que nunca había podido determinar, algo que generaba en mi una tristeza infinita. Aquí, en cambio, en esta pocilga lúgubre y hedionda recuperaba pronto mi felicidad y me sentía de nuevo hombre (Los maniáticos 12).

La insistencia sobre el motivo corporal como núcleo de algunas narraciones ("El nene", Los maniáticos, "Los coleccionistas de escupidas", El Grongo) o como una presencia fuerte ("El apartamento", "La cola", El Grongo, "La cámara", Los maniáticas, "Las amistades del Sr. Szomogy", Ocho modelos de felicidad), vinculan a este escritor con Quevedo y Rabelais ${ }^{23}$ y recuerdan esa confluencia de elementos que Erich Auerbach ${ }^{24}$ describía en el estilo del segundo, como la mezcla del realismo con la sátira y lo didáctico, las bufonadas groseras, el poder de imitación verbal, el nivel estilístico cómico del grotesco, que Giovanni Meo Zilio ha analizado en su estudio sobre la repetición en los cuentos de este escritor. ${ }^{25}$

El narrador de "El apartamento", después de haber destacadola importancia de la acción de defecar en la vida del hombre, de evocar los artefactos del baño de Hemingway y el perfeccionamiento de la moderna industria en "la grandeza de esta ceremonia", puntualiza por medio de observaciones críticas, un discurso que tiende a modificar la concepción tradicional sobre ese acto:

La gente no era consciente, pero hablaba mucho de esto aunque en términos tabuados y jocoso-despectivos. Estoy estreñido, ando mal, seco de vientre, tengo que tomar un laxante, eran frases corrientes que denotaban la preocupación de los hombres por la vida del intestino y que a veces se mezclaban con estrofas tangueras "tu piel, tu piel, magnolia que beso la luna" (El Grongo 97).

Es posible advertir la connotación ideológica al señalar la presencia del lenguaje alusivo - en lo que atañe a estos hechos naturales-para desterrar tal actitud. La observación no se detiene en el desenmascaramiento, actúa con energía en la misma escritura. Y más que puntualizaciones oportunas y casuales, éstas, en su diseminación, forman parte de la estética de la narrativa de Julio Ricci, quien en el prólogo de El Grongo (i-vii) es bien explícito, cuando hace referencia al cultivo de "la literatura asqueante", olvidada por la estética tradicional. El

\footnotetext{
${ }^{23}$ Domingo Luis Bordoli observa en el prólogo al tercer libro de Julio Ricci: “No hay palabra que no tenga tránsito en este desenfadado rabelesiano. Sorprendeel papel que desempeñan las necesidades orgánicas. Están casi siempre al servicio de situaciones cómicas" (en Julio Ricci, Ocho modelos de felicidad, op. cit., 7-8).

${ }^{24}$ Erich Auerbach, Mimesis. La representación de la realidad en la literatura occidental (México: Fondo de Cultura Económica, 1979), 2" reimpresion, "El mundo en la boca de Pantagruel", 245-264.

${ }^{25}$ Giovanni Meo Zilio, "Un estilema sintomático en Julio Ricci, Materiales para un estudio del cuento uruguayo", Thesaurus (Bogotá: Boletín del Instituto Caro y Cuervo, 1986), t. 41, 1-50.
} 
prólogo, más que un fugaz principio introductorio a los relatos, compone también la escritura de esos motivos marginales de la literatura como práctica decidida e intencionalidad expresa, con claras connotaciones axiológicas e ideológicas -la elección dèl motivo siempre rechazado por los escritores por ser abyecto, las necesidades fisiológicas, la mención de lo "bajo" - y parece querer cambiar de manera consciente las relaciones que nuestra cultura y por lo mismo, nuestra literatura, ha establecido con el cuerpo y su funcionamiento.

A pesar de la estética que lo ciñe dentro de la literatura del realismo urbano y social, este escritor tiene más de un puntoen común con Felisberto Hernández ${ }^{26}$ y es a través de esta relación con Felisberto cómo algunos cuentos suyos comparten con textos de escritores uruguayos en apariencia alejados de su narrativa como Tarik Carson o Armonía Somers, extrañas asociaciones, invenciones no menos extrañas y también el ejercicio del discurso poético, más allá de las semejanzas con L. S. Garini, que algunos críticos han señalado con acierto. Sus cuentos, en la propuesta de la representación del lenguaje popular, tienen el don de inventar nuevas situaciones y nuevas palabras, no siempre orientadas por el "buen gusto" sino por la sátira. Textos como "El gamexán" único en que el paisaje, cielo y mar montevideanos acompañan el relato con notoria presencia-, "Las amistades de Sr. Szomogy", "El Shoijet", "Las operaciones del amor", "Juancito" entre otros, son seguramente antológicos. Desafiando los temas vedados a las convenciones de la literatura tradicional, por ejemplo la crueldad, este autor describe de manera tan densa como el memorable "El pajarito de los domingos"(El sonido blanco) de María Montserrat, o el absurdo de la solitaria vida de un viajero rioplatense en Italia, que vibra felisberteanamente, con la fantasía de amor por una silla en "El apartamento" (El Grongo). Así, este narrador cuya manifiesta libertad de imaginario convive con buena parte de los escritores uruguayos, ${ }^{27}$ integra una de las franjas más singulares de la literatura rioplatense actual.

${ }^{26}$ Matilde Bianchi, "El lunatismo en la obra de Felisberto Hernández y de Julio Ricci". He visto los originales de esta ponencia leída en Paris el 5 de diciembre de 1987, en la sesión "Autour de Julio Ricci", por gentileza de la autora (en prensa).

${ }^{27}$ Véase en referencia a esto mi estudio "Discurso ficcional y discurso crítico en dos cuentos de las escritoras uruguayas Armonía Somers y Cristina Peri Rossi", Femmes des Amériques (Université de Toulouse Le-Mirail, 1986), 241-247. 